\title{
VASALLAJE DEL SEÑORIOO MUSULMÁN DE CREVILLENTE A JAIME II DE ARAGÓN
}

Por

JUAN MANUEL DEL ESTAL

En la historia de la ocupación y conquista del Reino castellano de Murcia por Jaime II de Aragón (año 1296), destaca sobremanera un hecho singular, protagonizado por el gobernador o ra'ís de Crevillente, Ahmad Abu Dja'far, el 4 de mayo, y pocos días después, el 17, por su heredero y sucesor en el cargo, Muhammad ibn Hudayr. Uno y otro acataron la soberania de Jaime ll sobre el entero Reino de Murcia, al par quie se pronunciaban sus dependientes y leales vasallos (1).

Tal conducta es reveladora de muy diversos sucesos. En primer lugar es preciso admitir la existencia de un señorio musulmán en el reino castellano de Murcia, autónomo e independiente, bajo el protectorado de Castilla, el Señorío de Crevillente.

Todo ello difiere de la conducta general que siguió la casi totalidad de las ciudades musulmanas del reino hudita murciano, al oponer resistencia armada al Infante Don Alfonso de Castilla, a raíz del Pacto de Alcaraz (1243), el que desecharon abiertamente, a excepción de la capital murciana y el Señorio de Crevillente, debiendo emplear la fuerza el futuro Rey Sabio para reducir a la soberanía de Castilla el entero reino murciano, por espacio de numerosos años (1243-1250-1260/65)(2).

La política del infante castellano y luego rey. Alfonso $X$, el Sabio 11252 1284) en la repoblación del Reino Hudita murciano fue diferente a la seguida por su padre, Fernando III, el Santo, en las ciudades del medio y bajo Guadalquivir, evitando la evacuación masiva de su originaria población musulmana y limitando ésta estrictamente a los cuadros directivos urbanos que más destacaran en la lucha armada anticastellana (3).

11) GUICHARD, P. Un señor musuimán en la España cristiana: el Ra'is de Crevillente (1243-13181, Alicante. 1976 .

(2) ESTAL, J. M. del, Conquista v anexión de las tierras de Alicante, Orihuela, Elche y Guardamar al Reino de VaJencia por Jaime I/ de Aragón. Alicante, 1982, pp. 37-80.

(3) ibid 
La existencia de un señorío sarraceno en el protectorado castellano de Murcia es con todo un hecho insólito y altamente revelador de la política territorial de Alfonso el Sabio. Este monarca hubo de recurrir, ante la tenaz resistencia armada de casi todos los núcleos urbanos del Reino de Murcia, a toda suerte de pactos y negociaciones para arrancarles la capitulación y vasallaje, firmados formalmente en Alcaraz.

Ésta debió ser la coyuntura circunstancial del arráez de Crevillente, que prefirió acogerse al protectorado de Castilla y jurar vasallaje a su monarca, a oponer resistencia armada, al objeto de mantenerse en el poder y conservar el gobierno de la ciudad. Así se desprende del favor real que gozó al verse confirmado en su cargo y ampliado su gobierno a las alquerías de Cox. Albatera y Chinosa, sucesivamente (4).

Vasallaje que no impidió al monarca castellano in tegrar este señorío en en amplio alfoz de Orihuela, el 1266, al par que Guardamar (Almodóvar) y Abanilla (5). Pero sin perder su independencia y soberanía señorial, según se desprende del Llibre dels feits o Crónica de Jaime l, quien a su paso por Orihuela (24-XII-1265) recibió el homenaje del ra 'ís de Crevillente, poniéndose a su entera disposición: "E quan nós fom en Oriola venc-nos lo fill de Banud el Arrais de Crivillèn, e dix-nos... que feria tot ço que nós manàsseme, e que els nostres hòmens poguessen entrar en Crivillèn salvament e segura; e venia a nós que ens rendés aquells dos castells que havia e que ens podiem ajudar del seu així com del nostresn (6). Prueba inequivoca de hallarse al frente de aquel señorío y poder por ello disponer del mismo y servirse de sus castillos y fuerza armada para sofocar la rebelión mudéjar murciana, causa, como es ya sabido, de su expedición por estas tierras alicantinas, años 1265 y 1266 (7).

Tal status político del Señorio de Crevillente, con cierta soberanía propia, dentro del Protectorado de Castilla en el reino murciano, perduró intacto hasta la instauración de la nueva hegemonía aragonesa, por obra de Jaime II, el año 1296.

Y aquí es donde vuelve a producirse aquella situación anómala, de la que hablábamos al principio de este trabajo, al aludir a la excepción del Señorío de Crevillente, cuando, a la inversa del resto del reino murciano, hostil a la causa de Aragón, aquél se pronunció a favor de la nueva soberanía, enviando su ra'ís, Muhammad ibn Hudayr, una carta elocuente a Jaime II 117 mayo 1296), para hacerle saber que se había sumado por entero a su causa, haciendo colocar sobre la torre de su castillo el vexillo real de Aragón, en testimonio fehaciente de su más leal obediencia y vasallaje (8). Si bajo la soberanía castellana 11243 1296) el Señorío de Crevillente disfrutó de cierta soberania e identidad propia musuimana, dentro del reino castellano de Murcia, lo que constituyó una excepción política sin paranqón en el Sharq-al-Anda/us, baio dominación cristia-

(4) GISBERT Y BALLESTEROS, Historia de Orihuela, 1, Orihuela, 1901. pp 471-472. GUICHARD, op. cit, p. 21

15) ESTAL. J. M. del, Documentos inéditos de Alfonso' $X$ el Sabio y de su hijo el infante don Sancho, Alicante, 1948, pp. 205-210.

(6) Crónica, 422, ed SOLDEVILA, Les Quatre grans Cróniques, Barcelona, 1971, p. 153.

(7) ESTAL, J. M. del, Conquista y anexión..., pp. $44-52$ y $154-158$

(8) GUICHARD, op. cit., pp. 68-71. ESTÁL, J. M. del, "Corpus documental dea Reino de Murcia bajo la soberania de Aragón (1296-1304/5 tw, Colección de Documentos Medievales Alicantinos, 1/1. Alicante, 1985, número 66, pp. 176-179. 
na, ahora, bajo la nueva soberania de Aragón (1 296-1318), va a incrementarse todavía más su poder e importancia, con irradiación creciente al entero Reino de Murcia.

En correspondencia al leal vasallaje jurado por el ra'is de Crevillente, Jaime Il acogía prometedor bajo su real tutela y protección a todos los mudéjares del Reino de Murcia, confirmándolos en la posesión legítima de todos sus bienes, derechos y libertades, siempre y cuando ellos lo reconocieran y acataran por su rey y señor natural: "por senyor e por rey del regno de Murcia", confiando la vigilancia y ejecución de tan noble cometido ual dito arrayç de Crivillen, el fiel e amado nuestro Mahomet Abinhudell... que él que vos asegure de part nuestra, vos viniendo a nuestra senyoria e reconociendo nos por senvor e rev del Regno de Murcian (9).

El Señorio de Crevillente se vela de este modo convertido en un muy válido interlocutor entre la Corona de Aragón y los muchos musulmanes que poblaban todavía mayoritariamente el Reino de Murcia. Lo que revestía particular interés, cara a un más fácil y mayor afianzamiento de la nueva soberanía, recién instaurada, $y$ frente a una hostilidad general reinante castellana, en los núcleos urbanos más importantes del Reino de Murcia, a excepción de la capital, como queda ya expuesto (10).

Al objeto de probar documentalmente la presencia numerosa todavía de musulmanes o mudéjares en el Reino de Murcia, "bajo la soberanía" en aquella década (1296-1304/5) de Aragón, ofrecemos en un anexo documental los testimonios referentes al caso.

Apenas transcurridos seis días de la ocupación aragonesa del castitlo y villa de Alicante (22 abril 1296), se preocupa Jaime II de los sarracenos residentes en Elche, mediando ante el merino mayor del noble don Juan Manuel, el caballero don Sancho Jiménez de Lanclares, para que en nombre de su señor, adolescente todavia y menor de edad por aquella fecha, se revoque la orden de expu/sión de aquéllos que estuvieran emparentados o tuvieren sus familiares residentes en la villa de Alicante, asímujeres como niños, permitiendo en todo caso que, si ha de llevarse a cabo la citada evacuación, se les permita al menos que "puedan salvament e segura con todos sus bienes e sus cosas venir tro al Portixol", para integrarse a la comunidad alicantina (11). Donde queda bien claro que un número indeterminado de vecinos de Alicante, cristianos y moros, puntualiza textualmente, residian o tenían familiares suyos en Elche, constituyendo un considerable porcentaje del núcleo urbano de una y otra villa, en demostración de que la población musulmana, medio siglo después de instaurada la soberanía cristiana por Alfonso X el Sabio en el Reino de Murcia, seguía asentada en gran parte en los centros urbanos alicantinos, formando todavía el núcleo humano principal. Cierto que los mudéjares permanecían también en no menor parte dispersos por el campo, in tegrando mayoritariamente la población rural, pero sin que ello comportara en modo alguno su ausencia en la ciudad

\footnotetext{
(9) Ibid., número 79, pp. 189-190.

$110)$ ESTAL, J. M. del, Corpus documental, pp. 54-69.

(11) Vease esta carta de Jaime II (Guardamar, 27 de abril de 1296) en anexo documental número 1
} 
donde detentaban aún numerosas e importantes actividades artesanales y otros servicios urbanos.

En términos similares se expresa otro testimonio de Jaime $\|$ ante el citado merino mayor de don Juan Manuel, señor de Elche, exponiéndole que él no puede vedar la libre circulación por tierras alicantinas y del entero Reino de Murcia a los moros residentes en la villa ilicitana, si bien ésta por entonces $(11$ de mayo de 1296 ) no le obedeciera todavía, por hallarse bajo el señorío del noble Juan Manuel. "Onde vos façcemos saber, añade, que nos no podemos veedar que los moros de don Johan Manuel no vaguen a nuestros logares e de los nuestros logares a la tierra del dito don Johanm(12). Ahora sí, no por ello podrán llevarse indebidamente lo que les pluguiere, ya que en tal caso hará que lo devuelvan de inmediato sin remisión "Nos les faremos tornar» (ibíd.). De donde se infiere que los mudéjares alicantinos gozaban de buena suerte de fueros $y$ privilegios, comunes por el momento a todos los moradores, ya fueran cristianos o musulmanes o judíos, por el interés del propio monarca en asegurar la permanencia en el Reino de Murcia de todos estos contingentes humanos en el mismo, en beneficio de su mayor desarrollo socioeconómico y creciente prosperidad.

Las disposiciones del monarca aragonés a favor de las aljamas y comunidades sarracenas y judías en todo el Reino de Murcia se multiplicaron en este sentido, imponiendo a sus altos funcionarios el estric to respeto de todas sus libertades, costumbres $y$ fueros $(13)$.

Valga de elocuente testimonio la provisión real que dirigió Jaime ll a todos los musulmanes del Reino de Murcia en los siguientes términos bien expresivos al respecto:

1296, mayo 20. Murcia.

Don Jaymes etc.

A todos los moros del Regno nuestro de Murcia de qualesquier logares sean la sua gracia e bona voluntad.

Facemos vos saber que el fiel e amado nuestro Mahomet Abinhudell (Muhammad ibn Hudayr), arrays de Crevillen, nos rogo muyto que nos que deviessemos assegurar vos e vuestros bienes e tornariades a vuestros logares e reconoçierades nos por senyor e por rey del Regno de Murcia e seriedes en nuestra fiedeltat, e nos querientes vos amar assi como los nuestros antecessores an amado los moros, que eran dejus lur senyoria, avemos acomendado al dito arrays que él que os assegure de part nuestra, vos viniendo a nuestra senyoria e reconoçiendo nos por senyor e rey del Regno de Murcia segunt que dito es. Porque nos vos femos saber que aquell asseguramiento que el dito arrays vos fara en esta rayyon que lo avremos nos por firme e lo ternemos e lo observaremos e lo faremos tener e observar bien e complidament.

(12) Véase esta carta de Jaime li en anexo documental número 2

(13) ESTAL, J. M. del, "Confirmación de fueros a la ciudad y Reino de Murcia por Jaime ll de Aragón, 1296-1304 ", Miscelánea Medieval Murciana, IX, 1982, pp. 239-292 
Dada en la ciudad de Murcia, veynt dias andados del mes de mayo, anno predicto $(1296)$.

Guilleimus de Solanis mandato regio.

En ella nos certifica el monarça aragonés la existencia de una población considerable mudéjar en el Reino de Murcia, la que obviamente quiere atraer a su obediencia y servicio, para cuyo objetivo ha hecho saber al ra'ís de Crevillente, su leal servidor y fiel amigo, que es su propósito confirmarles el disfrute de todas sus libertades y bienes de fortuna, si lo acatan como a su nuevo soberano y señor natural. Y este es el cometido de la presente carta, en la que aduce como garante digno de todo crédito de su voluntad real, al propio arráez de Crevillente. Muhammad ibn Hudayr, cuya relevancia política les es bien conocida.

Otro dato a destacar de este testimonio real es la confesión del monarca de pretender con tal actitud benefactora expresarles su amor y deseo de ayudarles y protegerles, al igual que to hicieran sus antecesores en el trono de Murcia. aludiendo implícitamente sobre todo a Alfonso el Sabio y a sus sucesores en el gobierno de aquel protectorado castellano.

De todo ello se deduce que la población musulmana siguió gozando del favor real durante la precedente soberania castellana en el Reino de Murcia, pese a las medidas tomadas por la corona de mayor control de los mudéjares, a raíz de la sublevación de los mismos, en los años $1264 / 66$.

Y ahora Jaime II no hace más que reafirmarles solemnemente, al ponerles por testigo de excepción al ra'ís crevillentino, que seguirá en la línea protectora de sus predecesores, siempre y cuando lo acojan por su soberano legítimo, frente a Fernando IV de Castilla, con quien se halia en guerra, por la posesión del Reino de Murcia. A este propósito le interesaba sobremanera contar con la aprobación y acatamiento espontáneo de la todavía cuantiosa población musulmana del mismo, para domeñar mejor por este medio la persistente y dura resistencia castellana $(14)$. $Y$ en tal contexto histórico-político han de interpretarse tales actos del monarca aragonés.

Entre los que hay que subrayar la provisión real de Jaime II IValencia, 20 de agosto de 12961, por la que notificaba a los mudéjares residentes en el señorío ilicitano del noble don Juan Manuel, así en la villa como en todos sus términos, su firme resolución a hacer valer y respetar todos sus derechos, franquezas, libertades, donaciones, mercedes, gracias, favores, viejos usos y costumbres, de que gozaran tiempo atrás, bajo el gobierno de sus antiguos señores, los nobles don Juan Manuel y su esposa, la condesa Doña Constanza, garantizándoles que así lo hará cumplir y urgirá su ejecución puntual a todos los procuradores generales, bayles y justicias del Reino de Murcia (15). Idéntico sentido de justicia hacia la población musulmana de Elche impulsa a Jaime ll a mediar ante el merino mayor de don Juan Manuel, el noble don Sancho Jiménez de Lanclares (Orihuela, 11 de mayo de 1296), para urgirle la devolución de "VIl cabeças de vaccas, una espada e una lança e otras cosas" que "hommes de vuestra companya an salteado a los moros del fiel nuestro Remon Sa

(14) ESTAL, J. M. del, Reino de Murcia bajo Aragón. Alicante, 1985, pp. 3-85

(15) Vide anexo documental número 3 
Coman (16), por no hallarse dispuesto a tolerar ni dejar impunes tales actos de rapiña y vandalismo contra cualquiera de sus súbditos del Reino de Murcia, al margen en absoluto de su confesionalidad religiosa. El apoyo y protección real a la población musulmana, asi urbana como rural, de todo el reino, sigue siendo total.

E idéntica actitud protectora desplegó Jaime II a favor de los mudéjares y judíos de otras muchas villas y lugares del reino entero de Murcia, destacando entre otros Cartagena, Mula, Alguazas, Albudeite, Orihuela, Callosa, Petrel, Guardamar, Alicante, etcétera, como podrá comprobar satisfactoriamente el lector en nuestras dos publicaciones siguientes (17).

Y tornamos ahora al Señorío sarraceno de Crevillente para corroborar documentalmente la condición vasallática del mismo, bajo la obediencia y soberania de Aragón.

Destaca en primer lugar la carta amistosa y cordial de Jaime II al ra'ís de Crevillente, Ahmad Abu Dja'far, el Aliafar de las crónicas cristianas, en la que le ruega faculte a los moros allí acogidos dentro de su ciudad, procedentes de Alicante (de donde habian salido an te el avance militar de las tropas aragonesas, por miedo a la actitud desconocida que pudiera adoptar el monarca frente a la población musulmanal el regreso a la villa alicantina, a cuantos lo prefieran, con todo su ajuar y demás bienes: "Rogamos vos e vos requisimos que los sobredichos moros nuestros de Alacant e de los otros logares nuestros que son en Crivillen lexedes yr salvament e seguir para Alicant, con todas sus cosas e sus bienes que han hi, sens algun embargament" (18).

Y la respuesta del ra'ís fue satisfactoria plenamente, a sólo juzgar por la carta más que elocuente del nuevo arráez crevillentino, Muhammad ibn Hudayr, con fecha del 17 de mayo de 1296 , en la que le rendia homenaje y juraba fidelidad por su dios, su ley y la qibla de Mahoma, al par que se proclamaba su más fiel vasallo y servidor leal (19).

Y una semana después premiaba Jaime II tan sobresaliente fidelidad y leal vasallaje con la confirmación de su rango directivo y cargo de gobernador del Señorío de Crevillente, en condición de arráez del mismo, en disfrute pleno de todos los derechos y atribuciones de que gozaran sus antepasados, bajo sus predecesores, en todos sus lugares, como Albatera y Cox y demás pertenencias del mismo, por lo que añadía "confirmamus vobis dicto Hammaeto et vestris perpetuo locum de Crivillen, cum locis vocatis Cox et Albatera ad dictum locum de Crivillen spectantibus et cum omnibus aliis pertinentiis universis, de suerte que vos dicho arráez $y$ los vuestros hayais y tengais a perpetuidad en nombre nuestro y de nuestros sucesores el referido lugar de Crevillente y los demás lugares citados, con todos sus términos, al modo como vos lo teneis en condición de Arráez y de la misma manera en que vuestros predecesores lo hu-

\footnotetext{
(16) Vide anexo documental número 4.

(17) ESTAL, J. M. del, "Confirmación de fueros a la ciudad y Reino de Murcia por Jaime Il de Aragón", Miscefánea Medieval Murciana, IX, 1982, pp 239-292; Íd. . Corpus documencal del Reino de Murcia bajo Aragón, Alicante. 1985, pássim

(18) Vide anexo documental número 5

(19) Vide supra, nota 8 y textos correspondientes
} 
bieron y tuvieron tal Señorio en el pasado, en tiempos de nuestros predecesores de Castilla en el Reino de Murcian (20).

Testimonio este de particular relieve para la comprobación histórica de que el Señorío de Crevillente fue reconocido en el ámbito territorial y marco jurídico de vasallaje a Castilla, en tiempos ya de Alfonso $X$ el Sabio, quien, por su parte, según confesión elocuente del propio Jaime II, respetó su autonomía soberana, si bien bajo el vasallaje castellano, constituyendo en consecuencia un verdadero Señorio musulmán independiente, bajo el protectorado castellano en el Reino de Murcia. Y ahora Jaime II, impulsado por idénticos motivos, de contar con un aliado musulmán poderoso, dentro del propio Reino de Murcia, acepta complacido su personal homenaje y leales servicios a la Corona de Aragón, confirmándole en justa contraprestación las numerosas franquicias y fueros aludidos.

Hay que destacar entre los numerosos privilegios otorgados por el monarca, de manera muy especial, la provisión real del 23 de mayo de 1296 , por la que confirió al ra'ís de Crevillente, Muhammad ibn Hudayr, el alto y honroso cargo de Justicia de todos los sarracenos del Reino de Murcia, desde Orihuela, Guardamar y Alicante haste Beniopa (junto a Gandia), al igual que tiempo atrás to ejerciera tal oficio de oidor y juez de las causas civiles y criminales, bajo la soberania de Castilla, en el Reino de Murcia (21), de todos los musulmanes alicantinos.

Es significativo de verdad el privilegio del fuero propio musulmán, otorgado por Jaime $\mid l$ al Señorio de Crevillente, en premio institucional a los servicios tan singulares prestados, antes a la Corona de Castilla y ahora a la de Aragón, dentro del Reino de Murcia, en el que se mantuvo por tantos años, más de medio siglo, desde el 1243 al 1318 , en obediencia y leal vasallaje a las dos alternantes soberanías cristianas, castellano-aragonesa, convertido en un auténtico bastión sarraceno de gran valor estratégico para la causa política del reino cristiano de Murcia, frente al musulmán de Granada. Éstas sobre todo son las razones primordiales que aconsejaron a los referidos monarcas cristianos, así de Castilla como de Aragón, a pactar con los sucesivos arraeces del Señorío de Crevillente, para asegurarse por su medio mejor la obediencia pacífica de la numerosa población mudéjar, mayoritaria sin duda, del Reino de Murcia, y servirse de su mediación en repetidas negociaciones con los reinos islámicos de Ifriqiva, Tremecén y Marruecos, al otro lado del Estrecho, y del propio reino nazarita de Granada (22).

Las disposiciones por ello del monarca aragonés a beneficio del arráez de Crevillente se multiplicaron sobremanera, a nivel político, judicial, administrativo, institucional y hasta económico. Así nos lo certifica su Provisión real del 23 de mayo de 1296 a favor de Aben Natalaziz, esposa del ra'is crevillentino $A h$ man ibn Hudayr. Hija aquélla del rey hudita de Murcia Muhammad $A b \bar{c}{ }^{\circ} A b d$ Allāh b. Hud, que gobernó la comunidad musulmana de la Arrixaca (12661279 ), bajo el protectorado castellano de Alfonso el Sabio (23) y a quien este

(20) Vide anexo documental número 6

121) Vide anexo documental número 7

122) ALARCÓN Y SANTON, M. LOS documentos árabes diplomáticos del ACA, Madrid, 1940, pássim. MASSIA DE ROS, A., La Corona de Aragón y los estados del Norte de Africa. Política de Jaimell y Alfonso IV en Egipto, Ifriquía y Tremecén, Barcelona, 1951 , pássim

123) MOLINA LÓPEZ, E. aMurcia en el marco histórico del segundo tercio del s. Xlli, $1212-1258$ " Historia de la region murciana, ili, Murcia, 1981, pp. 258-261 
monarca denominó en su carta (Vitoria, 2 de marzo de 1277) don Abodille Aben Hud, rey moro de la Arrixaca (24), heredó de su padre considerable hacienda, dentro de la propia ciudad de Murcia, la que ahora le confirmó complaciente el rey de Aragón en estos términos bien expresivos: a...per Nos et nostros laudamus, approbamus ac etiam confirmamus vobis, uxori predicti Arrayc et vestris totum hereditamentum quod habetis et tenetis in civitate Murcie, ex successione illustris Mahometi Abuabdille, olim Regis Murcie, patris vestri... (25).

Por la misma fecha en que Jaime II constituia al ra'ís de Crevillente, Ahmad ibn Hudayr, juez de todos los mudéjares del Reino de Murcia, particularmente de los que residían en las tierras desde Orihuela a Beniopa, o lo que es igual, desde el bajo Segura al bajo Serpis, por Gandía, ampliaba el señorío crevillentino con la donación de Beniopa, sito al NW de aquella ciudad valenciana (26).

Es bien claro que el propósito del monarca aragonés era granjearse el vasallaje más incondicional y absoluto del referido gobernador sarraceno, para asegurarse mejor por su medio la sumisión de la numerosa población mudéjar del entero Reino de Murcia y así obviar un peligroso enemigo, pudiendo dedicarse en consecuencia al sometimiento armado de los rebeldes castellanos, a los que lograría domeñar después de tres años de lucha, largos, gracias, sin duda, al apoyo incomparable del arráez crevillentino, con su gestión diplomática de embajadas y negociaciones ante sus congéneres a favor de Aragón. Gestiones que no han sido hasta la fecha analizadas en profundidad y que hay que tener en cuenta a la hora de enumerar los factores diversos que coadyuvaron a Jaime Il en la conquista y sometimiento pleno del reino castellano de Murcia y consiguiente anexión formal a la Corona de Aragón.

La soberanía del ra'ís de Crevillente, sobre todo su señorío, que llegó a abarcar por estas fechas los lugares citados de Cox, Albatera, Aspe, Chinosa, Monóvar y Beniopa, conlleva, aunque parezca paradójico, el vasallaje espontáneo al rey de Aragón, como rey de Murcia. Y así vemos al caballero Ferrando Garcés de Rueda, comisionado por Jaime II, en condición de su procurador real, recibir el homenaje y jura de fidelidad de los "castiellos e logares de Asp. de Munthovar e de Chinosa e a reçebir homenatge e jura, seguhnt que fer se deve de los moros que son e habitan en los ditos logares e en sus terminos e a que la jura e homenatge recebudes, assegurar de part nuestra todos e cada uno de los moros de los ditos logares e de otros cualesquiera logares que venrran $e$ se sotçmeteran a la nuestra Senyoria... e a jurar aquellos castiellos de part nuestra al honrrado don Hamet Abenhudell, arrays de Crivillen, assi que los tenga por Nos e en vec e en nomne nostro e en nostra feeldat en tanto quanto a nos ploguiere ...» (27).

Todos los referidos castillos debería recibirlos de manos del procurador real el arráez de Crevillente, quien habría de gobernarlos en nombre y delegación del monarca aragonés, como gobernador feudatario del mismo, a quien prestaría el vasallaje debido en la persona del caballero Ferrand Garcés de Rue-

\footnotetext{
124) CODOM, I, documento LXXVII, pp. 96-97

(25) Vide anexo documental número 8.

(26) Vide anexo documental nứmero 9

(27) Vide anexo documental número 10.
} 
da, a quien deberla escuchar atentamente en cuanto le dijese (28). Términos estos últimos que nos revelan el alto grado de participación del ra'ís de Crevillente en la resolución de asuntos de estado, concernientes al Reino de Murcia y a la Corona de Aragón. cuya negociación prefiere confiar Jaime II al secreto de su enviado especial, Garcés de Rueda, y no a la palabra escrita y por ello desvelable de una carta, a tenor de cuanto sigue: "Sepades que nos avemos demandado al amado cavallero nuestro Fferrant Garces de Rueda algunas cosas que vos diga de part nuestra, porque vos rogamos que a/ dito... Rueda creades de lo que vos dixere de la nuestra parte... (29).

Era por cuanto queda dicho el arráez de Crevillente un gobernador musulmán vasallo del Rey de Aragón y un verdadero señor territorial de un vasto dominio, feudatario de Jaime II, a quien prestaba el acostumbrado homenaje feudo-vasallático, ora a él en persona o bien a sus procuradores delegados.

Asi lo vemos constatado de nuevo en el sucesor de Ahmad ibn Hudayr. Muhammad ibn Ahmad, al confirmarlo en su cargo de ra'is de Crevillente Jaime II (6 febrero 1298) y señor de Albatera y Cox y de todos los demás heredamientos ya conocidos de su padre $(30)$.

El papel en suma del arráez de Crevillente, en la abra conquistadora del reino castellano de Murcia por Aragón, así como en la captación del ánimo y voluntad de servicio de los mudéjares a la causa de Jaime II, fue de singular importancia e interés estratégico sin igual, debido sobre todo a su elevado caudillaje espiritual y político de gran parte de la población musulmana de/ Reino de Murcia.

\footnotetext{
128) Vide anexo documental número 11

(29) Vide anexo documental número 11.

(30) Vide anexo documental número 12
} 



\section{ANEXO DOCUMENTAL}

1296. abril 27. Guardamar

Carta de Jaime II al merino mayor del noble D. Juan Manuel, Sancho Ximénez de Lanclares, notificándole que, enterado de la orden que ha cursado de expulsión de Elche a cuantos vecinos, cristianos o moros, tienen sus padres o esposos en Alicante, recién conquistado por el monarca aragonés, les permita llegarse, le pide, más acá del Portichol, término alicantino, con todas cuantas cosas y bienes deseen llevar consigo.

ACA, Reg. 340 , fol. $51 \mathrm{r}$.

Nos Jayme por la gracia de dios Rey de Aragón, de Mayorca, de Valencia e Conde/ de Barcelona al amado Sancho Xemenes de Lanclares, merino mayor de la tierra de Don Johan Manuel/ en el Regno de Murçia salut et dilection. Femos vos saber que viemos una carta vostra que/ enbiastes a los hommes buenos de Alacant, en la qual yera contenido que ellos por sabado/ el primero vinient ouviessen echados de Elch sus fijos et sus mulleres con todos sus bienes. Et en/altra manera que vos los ende fariades todos echar. Por que vos requerimos e vos rogamos que vos/ fagades en tal manera que la gent de Alacant, qui son en Elch, asi Xnos como moros, con sus/ mugeres e sus fijos companyeros puedan salvamente segura con todos sus bienes e sus cosas venir/ tro al. Portixol. Dada en Guardamar, 27 días andados del mes de abrill en el anno de nuestro sennor de mill e doscientos noventa seys/.

11

1296, MAYO 11 . Orihuela

Carta de Jaime 11 al Merino Mayor del noble don Juan Manuel en las tierras del Reino de Murcia, Sancho Ximénez de Lanclares, en contestación a la queja formulada por éste, sobre el hecho de que algunos moros, vecinos de Alicante, se llevaron consigo algunas cosas, pertenecientes al señorio de aquél, respondiéndole que en modo alguno puede impedir que los moros de esas tierras pasen de un lugar a otro con libertad, pero que si descubre que se llevasen indebidamente algo, que tenga por seguro que los obligará a devolverlo cuanto antes. 
ACA, Reg. 340. fol. $53 \mathrm{v}$.

Don Jayme por la gracia de dios etc. al amado Sancho Ximenes de Lanclares, Merino Mayor de la tierra que el/ noble Don Johan, fijo del Jnfant don Manuel ha en el Regno de Murçia, salut e amor.

Viemos uuestra Carta/ que agora Nos embiastes, por razçon de los moros de la tierra de don Johant Manuel, que desides que se lieuan/algunas cosas de la tierra de don Johan, axi como non deuen, a Alacant e a los otros nuestros/ logares e entendiemos lo que en aquella era contenido. Onde uos façemos saber que Nos no podemos uedar que los/ moros de don Johan Manuel no uaguen a nuestros logares e de los nuestros logares a la tierra del dito/ don Johan. Mas si los ditos moros de don Johan se aduçeren non deuidament algunas cosas de la tierra/ del dito don Johan, Nos las faremos tornar/.

Dada en Oriola, Xl dias del mes de Mayo. En el/ anno del nostre senyor de mill doçcientos nouenta e seis/.

Petrus de mandato Regis/ (31).

\section{III}

1296, agosto 20. Valencia

Confirmación por Jaime $\|$ a los sarracenos de Elche de todos los privilegios, franquezas, mercedes, libertades, donaciones, gracias y demás favores que, tiempo atrás, les otorgaran generosamente el infante Don Manuel y esposa, y su hijo el noble Don Juan Manuel, haciéndoles saber que urgirá a sus procuradores, bayles y justicias el respeto absoluto a todos sus fueros, usos y costumbres tradicionales.

ACA, Canc. Reg. Grat. 194, fol. 241 v.

\section{Sarracenorum de E|tx|}

Nouerint uniuersi quod Nos Jacobus dei gratia etc. Ad humilem supplicationem per uos fideles nostros Sarracenos de/ Eltx et terminorum suorum nobis factam, per Nos et nostros confirmamus uobis predictis Sarracenis ville de Eltx, termi/ norum eius et uestris perpetuo omnia priuilegia, franchitates, libertates, donationes, mercedes, gratias, bonos usus/ et consuetudines, quas et que habuistis et habetis a Nobilibus Jnfante dompno Manuel quondam/ et Comitissa ac. Joanne Manuelis usque ad tempora hodierna. Hanc autem donationem et confirmationem et con/ cessionem facimus uobis et uestris perpetuo sicut melius dici et intelligi potest ad uestrum uestrorumque saluamentum et/ bonum intellectum. Jta quod predictis uestris priuilegiis, franquitatibus, libertatibus, donationibus, gratiis et mer/ cedibus, bon is usibus et consuetudinibus utamini uos et uestri, secundum quos ex ipsis melius hactenus/ usi estis. Mandantes procu-

(31) Este mutuo respeto de Jaime ll al nobje don Juan Manuel v a las tierras y gentes de su señorio de Elche, y viceversa, tenfa por base la tregua firmada entre ambos, el 24 del precedente abril, por espacio de 26 días, esto es. riasta el 19 de mayo en curso, en virtud de la cual se obligaban a respetarse pleno iure recíprocamente. 
ratoribus, bajulis, Justiciis et uniuersis aliis officialibus et subditis/ nostris presentibus et futuris, quod predicta omnia et singula firma habeant et obseruent et faciant jnuiolabiliter/ obseruari et non contraueniant nec aliquem contrauenire permitant aliqua rationel.

Datum Valencie, decimo tertio kalendas septembris/, Anno domini millesimo ducentesiumo nonagesimo sexto/.

Signum (signo real) Jacobi dei gratia Regis etc.I

Testes sunt Jacobus de Xericha, Raymundus Fulchonis/, Jacobus Petri, Guillelmus de Angleraria, Arnaldus de Cardonal.

Guillelmi de Solanis disti domini Regis scriptoris, qui mandato ipsius/ hec scribi fecit et clausit, die, loco et anno prefixis/.

\section{IV}

1296, mayo 11. Orihuela

Carta de Jaime II a Sancho Ximénez de Lanclares, Merino Mayor de las tierras de don Juan Manuel en el Reino de Murcia, para lamentar el robo de siete vacas, una espada, una lanza y otras cosas más, que una compañía de hombres de Elche perpetraron contra los hombres moros de su fiel servidor, Ramón Zacoma, infringiendo tan llanamente la tregua y demás seguridades firmadas entre él y su señor, don Juan Manuel, rogándole por todo ello la devolución de lo robado a los moros referidos y que castigue debidamente a los culpables, como escarmiento por la violación de la tregua antedicha.

ACA, Reg. 340 , fol. 54 r.

Don Jayme por la gracia de dios Rey de Aragon, de Mayorcha e de Ualencia e conde de Barcelona al/ nostro amado Sancho Ximenes de Lanclares, Merino Mayor de la tierra que el noble don Johan Manuel, fijo del Infant don/ Manuel a en el Regno de Murçia, salu e amor. Sepades que Nos han feyto entender que homnes de/ uuestra companya an salteado a los moros del fiel nuestro Remon Ça Coma, e los han tollido VII cabeças de uaccas/, una espada e una lança e otras cosas. E marauellamos Nos end muyto, porque en Tregua e en Seguridat/ los uuestros homnes façen mal a los nuestros, porque uos requerimos e uos mandamos que a los ditos moros/ fagades entregament (enteramente) render lo que les es presso por una companya o qualesquier de Elch, e castigar uuestra/ companya e los homnes de Elch, que non fagan mal a la uuestra gent, pues Nos hauemos feyto manda/ a los nuestros homnes que no uos fagan mal, ni a la terra del dito don Johanl.

Dat en Oriola/, sexto jdus madij anno domini millesimo ducentesimo nonagesimo Sexto/ (32).

132) Persiste Jaime fl en el respeto inflexible por ambas partes de la tregua y paz firmadas con el noble don Juan Manuel en beneficio de la seguridad de las per sonas y bienes respectivos, durante los 26 días dados de plazo al señot de Elche para la entrega de la vilia, que cumplia ei 19 de maro de aquel mismo año 1296. 
1296, mayo 4. Cerco de Orihuela

Carta de Jaime II al ra 'ís de Crevillente. Ahmad Abu Dja'far, vulgo Aliafar, leal amigo de la Corona de Aragón, rogándole autorice el regreso a la villa de Alicante a cuantos mudéjares se encuentran asentados allí de pocos meses a esta parte, cuando por miedo al avance armado aragonés, abandonaron aquella villa, huyendo a este lugar más meridional y por ello más alejado del teatro inicial de operaciones, un mes antes, en los primeros días de abril de este mismo año. $Y$ habrá de permitirles llevar consigo cuanto deseen.
\end{abstract}

ACA, Reg. 340 , fol. 53 r.

Al amado Aliafar arrais de Crevillent/.

Don Jayme por la gracia de Dios Rey de Aragón, etc. al amado don Aliafar, arraiç de Crivillen, salut/ e amor. como algunos moros nuestros de Alicant e de otros logares nostros, que son en Crivillen se quieran/ yr con todas sus cosas para Alicant. Rogamos vos e vos requisimos que los sobredichos moros nuestros/ de Alicant e de los otros nuestros logares que son en Crivillen lexedes yr salvament e seguir para Alicant, / con todas sus cosas e sus bienes que han hi, sens alguns embargament, que non les fagades ni les lexedes/fer por alguno.

Data en el Cerco de Oriola, queatro días andados del mes de Mayo. en el anyo de nostre senyor/M. CC. XC. seis/ (33).

Scripsit Ferrer de Cortilio/.

\title{
VI
}

1296, mayo 23. Murcia

Provisión real de Jaime II por la que confirma al arráez de Crevillente, Ahmad ibn Hudayr, o el Abenhudell de las Crónicas, en el Señorío y posesión de Crevillente, Cox y Albatera, al igual que lo poseyera bajo sus predecesores en el Reino de Murcia, durante el Protectorado de Castilla, en premio a su lealtad y excelentes servicios.

ACA, Reg. 340, fol. 107 r.

Nouerint uniuersu quod Nos Jacobus etc. Ad instantiam et supplicationem Nobis pro parte nostri dilecti ac (. . borrado) Ahmmeti de Abenhudell, arrayç de Criuilien factam, per Nos et nostros laudamus, approbamus ac etiam confir/ mamus uobis dicto Hammeto et uestris perpetuo locum predictum de Criuillen spectantibus et cum amnibus alijs eorum pertinentiis uniuersis, jta quod uos dictus Arrayz et uestri/ habeatis et teneatis perpetuo pro Nobis et succe soribus

(33) Curioso uso de vocablos castellanos y valencianos conjuntamente. 
nostris dictum locum de Criuillen et alia loca predicta, cum omnibus eorum/terminis, prout et tenuerunt, temporibus Regni Castelle pre/ decessorum nostrorum in Regno Murcie. Mandantes per presens priuilegium nostrum procuratoribus, Vicarijs, baiulis, justicijs/ et uniuersis alijs officialibus nostris ac subditis, presentibus et futuris, quod presentem laudationem, approbationem et confirmationem/ nostram firmam habeant et obseruent et faciant inuiolabiliter obseruari et non contraueniant nec aliquem contrauenire permittant aliqua/ ratione.

Datum Murcie, decimo kalendas Junii anno domini millesimo ducentesimo nonagesimo Sexto/.

Signum (signo real) Jacobi dei gratia Regis Aragonum etc.I

Testes sunt Raymundus Fulchonis, vicecomes Cardone, Guillelmus de Anglerarial, Jacobus Petri (Jaime Pérez, hermano de Jaime II y Procurador General del Reino de Murcia), Jacobus de Xericha, Sancius de Antilionel.

Fuit clausum per manun Guillelmi de Solanis/.

\section{VII}

1296, mayo 23. Murcia

Provisión real por la que Jaime ll constituye al ra'ís de Crevillente, Ahmad ibn Hudayr o Abenhudell, en Juez ordinario de todos los sarracenos que moran en el Señorío de Crevillente y en Alicante. Orihuela, Guardamar y Beniopa, al igual que lo fuera en tiompos atrás, bajo la soberanía de Castilla, en el Reino de Murcia, por entero.

ACA, Reg. 340, fol. $107 \mathrm{r}$.

Nuerint uniuersi quod Nos Jacobus dei gratia etc. Codedimus uobis dilec to et fidelissimo Ahammeto Abenhudell, arrays de Criuillen/ quod sitis Judex Sarracenorum Regni nostri Murcie, scilicet Sarracenorum de Oriola et de alijs locis constitutis ab ipso loco/ de Oriola ultra usque ad Guardamar et Alacant et Benioppa, cum omnibus suis terminis inclusiue. Jta quod uos audiatis/causas ipsorum Sarracenorum et judicetis eos secundum Curiam ipsarum (34), prout consueuistis temporibus Regni Castelle predecessorum/ nostrorum in Regno Murcie supradic to. Mandantes per presentem Cartam nostram uniuersis Sarracenis conmorantibus jntra termino/ rum limites predictos, quod uos pro Judice ipsorum habeant et teneant prout habebant et consueverant temproribus Regni Castelle/ predictis. Mandamus etiam uniuersis officialibus et subditis nostris presentibus et futuris, quod presentem concessionem nostram firmam habeant et obseruent/ et faciant inuiolabiliter obseruari et non contraueniant nec aliquem contrauenire permitant aliqua rationel.

Datum ut supra/ (Murcia, 23 mayo 1296).

(34) La jurisdicción otorgada por Jaime ll al ra'is de Crevillente en materia judicial abarca a toda la pobiación mudéjar del Reino de Murcia conquistado hasta aquel momento, desde Alicante hasta la capital del mismo, de acuerdo a los fueron concedidos por Alfonso $X$ el Sabio y sus sucesores, hasta la fecha, $y$ a tenor de las propias leves e instituciones de sus aljamas, como lo venían haciendo tradicionatruente. El monarca aragonés le reconoce al Señor de Creviliente autonomía plena propia en el ámbito judicial para con los sarracenos todos del Reino de Murcia. 


\section{VIII}

1296, mayo 23. Murcia

Provisión real por la que Jaime Il confirma a Aben Natalaziz, esposa de Ahmad ibn Hudayr, ra'ís de Crevillente, el heredamien to que tenía en la ciudad de Murcia, por herencia de su padre, Ahmad Abu Dja'far o Alifar, rey de Murcia, años atrás.

ACA, Reg. 340, fol. 107 v.

Nouerint uniuersi quod Nos Jacobus dei gratia etc. Ad instantiam et supplicationem Nobis pro parte uestri Abnatalizaz, uxoris dilecti/ ac fidelis nostri Hammeti Abenhudell, arrayc de Criuillen factam, per Nos et nostros laudamus, approbamus ac etiam confirmamus/ uobis uxori predicti arrayc et uestris perpetuo totum hereditamentum quod habetis et tenetis in Ciuitate Murcie, ex successione/ Jllustris Mahommeti Abuabdille, olim regis Murcie, patris uestri. Jta quod habeatis et teneatis hereditamentum predictum pro/ ut ipsum hodie melius habetis et tenetis. Mandantes procuratoribus, vicarijs, baiulis, jisticijs, juratis et uniuersis alijs/ officialibus et subditis nostris presentibus et futuris, quod predictam laudationem approbationem et confirmationem nostram firmam habeant/ et obseruent et non contraueniant nec aliquem contrauenire permitant aliqua rationel.

Datum Murcie, decimo kalendas Junii, anno millesimo ducentesimo nonagesimo Sexto/.

Sig (signo real) num Jacobi dei gratia Regis Aragonum etc.I

Testes sunt Reymundus Fulchonis, vicecomes Cardone, Guillelmus de Angleraria/, Jacobus Petri, Jacobus de Xericha, Sancius de Antilione/.

Fuit clausum per manum Guilleimi de Solanis/ (vicecanciller de la curia aragonesa). 35

\section{IX}

1296, mayo 23. Murcia

Carta de donación de Jaime II al ra'ís de Crevillente, Ahmad ibn Hudayr o Abenhudell, de la villa y término de Beniopa, cerca de Gandía, en pago a los muchos y excelentes servicios prestados a la Corona de Aragón.

ACA, Reg. 340, fol. 108 r.-v.

(35) Tal confirmación real de los bienes de la esposa del ra'ís de Crevillente era un gesto bien elocuente de la voluntad de Jaime II de mantener las excelentes relaciones políticas de amistad con el mismo, en beneficio del buen gobierno del Reino de Murcia, poblado mayoritariamente por sarracenos o mudéjares a finales del siglo X|ıl. 
Nos Jacobus dei gratia Rex Aragonum etc. Attendentes grata et accepta seruitia per uos dilectum et fidelem nostrum Hammetum Abenhudell, arrayc de/ Criuillen Nobis exhibita et que per uos speramus de cetero exhiberi, damus et concedimus uobis locum de BENIOPA que est in Regno/ nostro Valencie, cum terminis, juribus et pertinentijs eiusdem, to to tempore uite uestre, jta quod uos teneatis dictum locum de Beniopa/ cum omnibus eius terminis, juribus et pertinentijs suis (...borrado: toto tempore uite uestre?) et colligatis et/ recipiatis siue colligi et recipi faciatis omnes redditus, exitus et prouentus et alia quelibet jura nostra et ad Nos in dic to loco/ pertinentia et pertinere debentia quoquo modo, diebus omnibus uite uestre et de ipsis redditibus, exitibus et prouentibus et alijs juribus/ supradictis prout de uestris fuerit libitum uoluntatis. Mandantes etiam per presentem Cartam nostra officialibus et subditis nostris/ uniuersis (fol. 108 v.) ad quos presentes peruenerint quod cum (...borrado: tengan conocimiento de este privilegio?) habitantibus et habitaturis in dicto loco de $\mathrm{Be}$ niopa et terminis suis, quos uobis uel cui uolueritis recipiant et obediant (...borrado: os reconozcan el derecho legitimo a todos los ingresos// redditibus, exitibus, prouentibus et alijs nostris juribus antedictis, diebus omnibus uite uestre. prout Nobis de ipsis tradere tenentur et debent/. Mandantes insuper procuratoribus, baiulis, justicijs et uniuersis alijs officialibus nostris presentibus et futuris quod nostram presentem donationem et ceoncessionem nostram firmam habeant et obseruent toto tempore uite vestre et non contraueniant, nec aliquem contrauenire permittant aliqua ratione/.

Datum Murcie, decimo kalendas Junii, anno domini millesimo ducentesimo nonagesimo Sexto/.

Sig (signo real) num Jacobi dei gratia Regis Aragonum, etc/

Testes sunt Reymundus Fulchonis, Vicecomes Cardone, Guilleimus de Anglerarial, Jacobus Petri, Jacobus de Xericha, Sancius de Antilionel.

Fuit clausum per manum Guillelmi de Solanis/ (Protonotario o Guardasellos de la Cancillería aragonesa).

\section{$\mathrm{X}$}

1296, junio 4. Huerta de Lorca

Carta de Jaime II por la que constituye al noble D. Ferrant Garcés de Rueda delegado suyo oficial para recibir del arráez de Crevillente, Mahomet Abenhudell, en condición de especial procurador real, los castillos de Aspe, Monóvar y Chinosa, con sus lugares respectivos y los moros residentes en ellos, debiendo éstos prestar jura y homenaje al lugarteniente real en testimonio del acatamiento de su soberanía, y rendir vasallaje al ra'is de Crevillente, leal servidor y fiel vasallo suyo, recibiendo a cambio la garantía y seguridad de sus personas y bienes.

ACA, Reg. 340, fol. 121 r. (Regestum de Regno Murcie).

Nos don Jayme por la gracia de dios Rey Daragon etc., establimos e ordenamos vos amado Cavallero/ nuestro Fferrant Garces de Rueda, cierto e special procurador nuestro, e damos pleno poder a reçebir per Nos/ e en nomne e en 
vec de nos e sotcmeter a nuestra senyoria los Castiellos e logares de $A S P$, de MONOVAR/ e de CHINOSA e reçebir homenatge e jura, segunt que fer se deve de los moros que son e habitan/ en los ditos logares e en sus terminos a a que la jura e homenatge recebudes, assegurar de part nuestra/ todos e cada unos moros de los ditos logares e de otros cualesquiera logares que venrran e se sotçmeterran/ a la nuestra Seynoria e recebida la jura e homenatge de los Moros avanditos, como dito es, a jurar aquellos Castiellos/ de part nuestra al honrado don Hamet Abenhudell, arrays de Crivillen, assi que los tenga por nos/ e en vec e en nomne nostro e en nostra feeldat, a tanto quanto a Nos ploguiere e nos avremos/por fierme e observaremos todo lo que faredes sobre las ditas cosas e cada unas assi como si por/ Nos personalmente era fevto. E/ en testimonio desto mandamos vos dar esta carta seellada con nuestro/ siello.

Dada en la Urta de Lorcha, quatro dias andados del mes de junio. En el anno de nuestro Seynor/ de M CC XC e Seys/.

\section{$\mathbf{X I}$}

1296, junio 6 . Huerta de Lorca

Carta de Jaime Il al ra'ís de Creviliente, Mahomet Abenhudell, notificándole que acaba de constitu ir procurador y delegado especial suyo para hacerse cargo de los Castillos de Aspe, Chinosa y Monovar, con sus respectivos lugares y términos, al noble caballero. don Ferrant Garcés de Rueda, quien deberá recibir el homenaje de los moros residentes en los mismos, pero siempre bajo la obediencia, jura y vasallaje a su egregia persona como Señor de Crevillente.

ACA, Reg. 340. fol. 122 v. (Regestum de Regno Murcie).

Don Jayme por la gracia de dios etc. Al amado y fiel nuestro don Amet Abinhudell, Arrays de Criuillent etc./ Sepades que Nos auemos damandado al amado cauallero nuestro Fferrant Garces de Rueda algunas/ cosas que uos diga de parte nuestra, porque uos rogamos que al dito Fferrant Garçes de Rueda creades de lo que/ uos dixere de la nuestra parte/.

Dada en la Orta de Lorcha, seys dias andados del mes de junio. En el annyol damuntditol. (1296).

\section{XII}

1298, febrero 6. Murcia

Provisión real de Jaime II de Aragón de confirmación en su cargo de ra's de Crevillente a favor de Muhammad ibn Ahmad, a raíz del fallecimiento de su padre, Muhammad ibn Hudayr, el Avenhudell de las crónicas cristianas, reconociéndole el gobierno de todo el Señorio de Crevillente, con los lugares de Cox y de Albatera, y demás pertenencias y bienes que posee en el Reino de Murcia, en la confianza de que sabrá servirle con la entrega $y$ lealtad de su difunto padre. 
ACA, Reg. 195, fol. $119 \mathrm{r}$.

Nouerint uniuersi quod Nos Jacobus etc. Attendentes quod uos Mahometus, filios Hameti Abinhudell, arrays de Criuilien, tanquam/ heres et successor eiusdem, ipso Hameto uiam uniuerse carnis ingresso succeditis et succedere debetis in locis/ de Criuillen, de Cox et de Albatera, ac in hereditamentis ipsius, sitis in Murcia et eius termino et in aliis bonis, que erant/ dicti Hameti, tempore mortis sue. Idcirco uolentes uos, dictum Mahometum speciali gratia prosequi et fauore ad/ humilem supplicationem pro parte nostra uobis factam (en lugar de vestra y de nobis) per Nos et nostram, ex certa scientia laudamus, approbamus et confirmamus uobis dic to Mahometo loca de Criuillent, de Cox, de Albatera in hereditamenta et bona predicta. Ita quod ipsa loca/, hereditamenta et bona habeatis, teneatis et possideatis pacifice et quiete pro Nobis et ad seriuitium nostrum, prout dictus pater uester/ pro Nobis tenebat eadem, et faciatis et compleatis Nobis et nostris ea omnia que dictus pater uester pro locis, hereditamentis et bonis/ predictis Nobis faciebat et facere et complete tenebatur. Mandantes per presens priuilegium procuratori Regni/ Murcie (Jaime Pérez, señor de Segorbe y hermano de Jaime Il) et uniuersis aliis officialibus et subditis nobis (sic, en lugar de nostris) Regni ipsius, presentibus et futuris, per presentem laudationem, appobationem et/ confirmationem nostram firmam habeant et obseruent et faciant ab omnibus inuiolabiliter obseruari et non contraveniant nex aliquem contrauenire/ permittant aliqua ratione. Datum in ciuita te Murcie. octauo jdus februarii, anno domini millesimo ducentesimo nonagesimo septimo (36)\%.

Sig (signo real) num Jacobi dei gratia regis Aragonum etc.l

Testes sunt Gondisaluus Exeri D'Arenoso, Jaspertus de Castro Nouo/

Jacobus Petri (Procurador General del Reino de Murcia), Raymundus de Urgio (alcayde de la vilia y castillo de Alicante), Atho de Lisone/.

(36) Por seguir la cancillería aragonesa entonces el estilo florentino de la Era de la Encarnación, la fecha escrita corresponde al año 1298. Sobre la sucesión de arraeces en el Señorío de Crevillente, vide GUICHARD, P. Un senor musuimán en la España cristiana. el ara'sh de Crevillente, 1243.1318, trad., Alicante, 1976. pp. 22-26. 